\title{
Estimation of Ecological Compensation Standards for Fallow Heavy Metal-Polluted Farmland in China Based on Farmer Willingness to Accept
}

\author{
Xue Xie ${ }^{1,2}$, Hualin Xie ${ }^{1, *} \mathbb{1}$, Cheng Shu ${ }^{1}$, Qing $\mathrm{Wu}^{2}$ and Hua Lu ${ }^{1}$ \\ 1 Institute of Ecological Civilization, Jiangxi University of Finance and Economics, Nanchang 330013, China; \\ tvxq_xue@163.com (X.X.); slendershu@163.com (C.S.); luhuanj@126.com (H.L.) \\ 2 School of Tourism and Urban Management, Jiangxi University of Finance and Economics, \\ Nanchang 330032, China; wuqing_carpediem@163.com \\ * Correspondence: xiehualin@jxufe.edu.cn; Tel.: +86-791-8397-9115
}

Received: 26 July 2017; Accepted: 11 October 2017; Published: 17 October 2017

\begin{abstract}
In the context of China's trial fallow policy; the heavy metal pollution of farmland is addressed via field surveys in Hunan Province, where the fallow policy has been implemented, and in Jiangxi Province, where it has not been implemented. We measured and analyzed willingness to accept (WTA) using the contingent valuation method (CVM). The conclusions of this study are as follows: (1) Farmer awareness of heavy metal pollution and pollution sources is higher in Jiangxi Province than in Hunan Province; (2) Ignoring the impact of other factors, the WTA of farmers is 902 (yuan / mu) in Jiangxi Province and 902.26 (yuan / mu) in Hunan Province. Considering the influence of the basic characteristics of the respondents using the parameter estimation method, the WTA of farmers is 839.34 (yuan/mu) in Jiangxi Province and 934.39 (yuan/mu) in Hunan Province. There is little difference in WTA between the two provinces, but both estimates are higher than the national compensation standards; (3) The factors that affect the WTA of farmers in Jiangxi Province are gender, education level, average annual income and per capita arable land. The factors that affect the WTA of farmers in Hunan Province are age, education level, family size, average annual income, per capita arable land area and farmer occupation; (4) At present, the means and methods of compensation for the implementation of the fallow policy are recognized by most farmers. The paper concludes with some policy suggestions based on above findings.
\end{abstract}

Keywords: fallow; heavy metal-polluted farmland; ecological compensation; farmer willingness; CVM; China

\section{Introduction}

Over the past 50 years, approximately $22,000 \mathrm{t} \mathrm{Cr}, 9.39 \times 10^{5} \mathrm{t} \mathrm{Cu}, 7.83 \times 10^{5} \mathrm{t} \mathrm{Pb}$ and $1.35 \times 10^{6} \mathrm{t} \mathrm{Zn}$ were emitted into the global environment. Most of this heavy metal pollution entered the soil, causing heavy soil pollution [1]. Urban development and the modernization of industry and agriculture have been accompanied by an excessive exploitation of minerals, which has led to substantial emissions from metal processing, machine manufacturing, smelting, electroplating and other industrial wastes [2,3]. Additionally, the excessive application of pesticides and fertilizers, leaching from feed waste, and the emission of other pollutants have resulted in the enrichment of heavy metals in farmland [4]. Heavy metal pollution in arable land can affect the quality and safety of agricultural products and cause serious harm to human health [5]. Therefore, farmland that is contaminated with heavy metals must be fallowed and reclaimed. Fallow refers to farmland that cannot be cultivated during the crop growing season [6]. Fallowing can restore the quality of cultivated land, allow ecological restoration and treatment, mitigate soil problems and enhance the development 
potential of agriculture to achieve "possession of the land" [7]. Hunan Province and Jiangxi Province are the major food provinces of China, and grain from these provinces is sold throughout the country [8]. However, frequent food safety incidents have raised concerns. Consequently, the Chinese government, on behalf of the Ministry of Agriculture, Ministry of Environmental Protection and 10 other ministries, issued a pilot land retirement program intended to "explore a pilot scheme for the implementation of a crop land rotation and fallow system". The program designated heavy metal-polluted areas in which to perform the pilot retirement. The primary scope of the project is the Chang-Zhu-Tan area in Hunan Province, which is severely polluted with heavy metals. According to the "2016 Implementation Plan for Heavy Metal-Polluted Farmland Fallow Pilot Management in Hunan", 100,000 mu (1 km² = $1500 \mathrm{mu})$ of heavy metal-polluted farmland in the Chang-Zhu-Tan area was allocated to be fallowed beginning in 2016. The annual subsidy was 1300 yuan per mu per year, with farmers compensated at a rate of 700 yuan per mu, and third parties at a rate of 600 yuan per mu.

Fallowing farmland is a new concept in China for protecting farmland systems. To date, research on the compensation standard for land retirement has not received the systematic attention of academia in China. Chinese scholars have primarily focused on foreign land retirement plans, their associated compensation projects [9-11] and the study of the standards for economic compensation mechanisms for farmland protection [12-14]. Wu et al. reviews and compares the land fallow system in different countries and regions of the world, and give some relevant policy implications for China: it should be based on the different degrees of land damage, the evaluation system and the subsidy accounting standard for fallow land are formulated, and the compulsory fallow and voluntary participation of the niche fallow are targeted [12]. Yang et al., analyzing and summarizing the pilot of crop rotation and fallow in Western countries and East Asia, found that based on the institutional framework of private property rights, the institutional goal of crop rotation and fallowing is mainly composed of regulating the agricultural capacity and preserving the ecological environment, but the background and the target are different between large-scale agricultural economic entity in Europe/America and small-scale agricultural economic entities in East Asia [11]. Also, many scholars in the international summarized the fallow policy in other countries. Suter et al. used data from six states to analyze the binary options involved in the Conservation Reserve Enhancement Program (CREP). Their study results showed that landowners respond positively to incentives, and that one-time incentives (compensation) provided along with the land reserve plan were more cost effective than the annual reduction of incentives (compensation) [15]. Johnson et al. assessed the CRP situation and found that the CRP provided the ecosystem services benefits that exceeded the compensation paid to farmers [16]. Feather et al., as well as Ribaudo, reported similar findings $[17,18]$. Xie et al. used the opportunity cost method to evaluate the suitability of an ecological compensation standard for a winter-wheat-fallow cropping system in a groundwater funnel area in Hebei. Based on their findings, they proposed a compensation standard of 518 yuan/mu [19].

At present, part of countries has adopted compensation standards for eco-conservation programs based on the opportunity cost method. For example, the Conservation Reserve Enhancement Program of the U.S.A. and China's returning-farmland-to-forest projects all use the opportunity cost as compensation standard [20-23]. However, the opportunity cost approach is rather one-sided because the government generally determines the compensation standard. Therefore, only the real economic interests are considered, while the willingness of the relevant stakeholders is ignored. While this approach may be reasonable with respect to ecological compensation standards, there is little enthusiasm among farmers for participation based solely on ecological compensation.

However, in the process of implementing land retirement of heavy metal-polluted farmland, the farmer is both the primary victim of the pollution and the executor of and a participant in farmland reclamation. One important factor affecting farmers' participation in the policy is the amount of compensation [24]. Economic benefits are the important factors influencing farmers' behavioral decisions and, to a large extent, can determine farmers' willingness to accept a policy. Developing a reasonable farmer-based compensation mechanism for fallow land could encourage the initiative and 
enthusiasm of farmers. Moreover, protection of the basic production, livelihood and interests of farmers should be considered to comprehensively and effectively facilitate the implementation of fallowing programs for heavy metal-polluted land in China [25]. However, there is a danger that farmers may exaggerate the extent of their losses to receive greater economic compensation. Therefore, the accurate accounting of compensation standards not only protects the basic interests of farmers but also enables the government to maintain reasonable costs while encouraging farmers to participate in policy. To this end, it is of great practical value to develop a rational and consistent compensation mechanism, for example, a compensation standard, and means of fallowing heavy metal-polluted land for implementing land retirement and enabling the remediation of heavy metal-polluted land.

The contingent valuation method (CVM) is a narrative preference assessment method [26]. This method was proposed by Ciriacy-wan trup, and Davis was the first to apply the CVM for assessing the natural environment [27]. The CVM identifies respondents' preferences through questionnaires. It can be used to deduce the distributions of respondent willingness to accept compensation in different environments, access to environmental resources and the value of economic services [28]. Unlike the opportunity cost method, the CVM is based on the willingness of the farmer. The CVM is widely used in the assessment of public resources, renewable energy and a variety of environmental protection projects [29-32]. The willingness to accept (WTA) is the minimum compensation amount required to secure a famer's consent to perform an action he otherwise would not perform (e.g., to participate in a governmental program for providing ecological services). Currently, foreign research primarily focuses on the willingness and behavioral preferences of landowners to provide ecological services [33-35]. The CVM also has a wide range of applications in various fields in China [36-38], particularly in the assessment of ecological compensation [39-41]. For example, based on 633 responses to a questionnaire, Zheng et al. investigated the willingness of residents to pay in the Dahuofang water supply area. The findings indicated that $68.2 \%$ of the residents had a willingness to pay for the Dahuofang water source protection area. The average willingness to pay was 93.81-137.55 yuan per person per year [42]. Based on the payment card type (PC) of CVM surveys in the South-to-North Water Diversion Project in Zhengzhou City, Zhou et al. showed that in 302 valid samples, $84.44 \%$ of the residents in the water area had a willingness to pay, and $89.8 \%$ of these residents were willing to pay a value of 10 yuan/month or less [43]. This study aims to establish an "ecological compensation mechanism for fallow farmland in heavy metal-contaminated areas", namely, a more specific and targeted approach to accurately reflect the environmental preferences of the farmers in fallow farmland in heavy metal-contaminated areas. The survey area involves Hunan Province, which has implemented a fallowing policy in the heavily polluted areas, and Jiangxi Province, which has not implemented a fallowing policy. The surveyed farmers have a wide range of regional characteristics, and we further examined the regional differences in their willingness to accept.

\section{Study Area}

The study area, Hunan Province, is approximately $21.18 \times 10^{10} \mathrm{~km}^{2}$ in size and is located along the middle reaches of the Yangtze River in central China between $24^{\circ} 38^{\prime}-30^{\circ} 08^{\prime} \mathrm{N}$ and $108^{\circ} 47^{\prime}-114^{\circ} 15^{\prime} \mathrm{E}$. The soil is dominated by red soil, followed by paddy soil and fluvo-aquic soil; the latter two are the main agricultural soils in Hunan Province. The farmland area was $4.15 \times 10^{4} \mathrm{~km}^{2}$ in 2014 in Hunan Province. Hunan is known as the "hometown of non-ferrous metals", and non-ferrous metal mining has led to heavy metal pollution of up to $28 \times 10^{4} \mathrm{~km}^{2}$, which means $13 \%$ of the total land area of Hunan Province is polluted by heavy metals. Jiangxi Province is approximately $16.69 \times 10^{10} \mathrm{~km}^{2}$ in size and is located in Southeastern China between $24^{\circ} 29^{\prime}-30^{\circ} 04^{\prime} \mathrm{N}$ and $113^{\circ} 34^{\prime}-118^{\circ} 28^{\prime} \mathrm{E}$. Jiangxi Province lies east of Zhejiang Province and Fujian Province, south of Guangdong Province, west of Hunan Province, and north of Hubei Province, Anhui Province and the Yangtze River. It is an important part of the Yangtze River Economic Zone. Jiangxi Province has diverse soil types, mainly red soil, paddy soil and eight other soil types. The total area of cultivated land in the province is $3.08 \times 10^{4} \mathrm{~km}^{2}$, accounting for $18.48 \%$ of the total land area. Jiangxi is one of the top 10 producers 
of non-ferrous metals in China and suffers from industrial and agricultural waste. According to the survey, the heavy metal pollution of paddy soil in Jiangxi Province is the most serious in the central region, with a level of $5.26 \%$ moderate pollution [44]. Therefore, the area of farmland affected by heavy metal pollution in Jiangxi and Hunan Provinces urgently requires withdrawal from farming. The development of ecological compensation standards for heavy metal pollution areas is required to make farmland areas fallow.

\section{Research Methods and Data Sources}

\subsection{Research Methods}

Many methods can be used to calculate the standard of fallow land ecological compensation, including the payment willingness law, the opportunity cost method, the income loss method, the total cost revision model, and the cost analysis method. Among these methods, the willingness to accept method is based mainly on the value assessment method of environmental value assessment theory. Currently, Chinese research on ecological compensation standards of fallow land primarily assesses the value of the willingness to accept method. Under China's current fallow policy, farmers have the right to choose whether or not to participate (some areas even do not have an option) and no choice of subsidy program opportunities. Therefore, under this provision, farmers' their true willingness cannot be inferred from their participation. By applying the stated preference (SP) method of the CVM, where in the respondents are informed of the purpose and background of the study, the true willingness of respondents can be determined. Therefore, researchers seek to explain the main purpose of this research and the relevant context. In this study, open guidance technology is used with the contingent valuation method (CVM) to analyze the ecological compensation standard of the farmland heavy metal area. Open guidance technology in the early application of CVM provides an easy method for data analysis and requests respondents to report the largest WTA.

\subsection{Questionnaire Design}

The data of this paper were primarily derived from the questionnaires returned by farmers in the heavy metal-polluted areas in Hunan and Jiangxi. First, the study villages were identified by searching for heavy metal-polluted areas online. Next, the authors met with representatives of the local land sector to discuss the heavy metal pollution of the entire area and other relevant issues. The need to investigate specific villages was determined based on these initial tasks. The author and several master's and doctoral students researched 10 villages with heavy metal pollution from the areas of Leping, Dexing and Guixi cities, and from Jiangxi Province, along with 12 villages that had implemented the land retirement policy in Changsha County, Xiangtan City, Chaling County, and Hunan Province. A total of 532 questionnaires were issued. Of these, 216 questionnaires were returned from Jiangxi Province, and 13 of these surveys were invalid, resulting in an effective rate of 93.98\%. Of the 316 questionnaires in Hunan Province, only one was invalid; thus, the effective rate was $99.68 \%$.

The questionnaire was divided into four parts. The first part primarily investigated the characteristics of the decision makers, including the age, sex and education level of the respondents and other basic socioeconomic information. This information was used to analyze the factors influencing farmer participation in compensation construction. The second part primarily investigated the farmers' awareness of farmland heavy metal pollution problems without providing any background material to the respondents. This information makes us know the extent of farmers' understanding of heavy metal pollution. The main question includes: Do you think heavy metal pollution has an impact on you? Do you know where it came from (multiple choice)? The third part was the core part of the survey and investigated farmer awareness of polluted arable land and their willingness to participate in the fallowing policy, which was used to obtain the WTA of local residents. The fourth part primarily investigated the farmers' preference for the form of compensation. The questionnaire was 
administered using the payment card method, with the content evaluated after all of the questionnaires were completed.

\section{Results and Analysis}

\subsection{Farmers' Awareness of Heavy Metal Pollution in Farmland}

(1) Statistical analysis of farmer awareness of the sources of heavy metal pollution in farmland

The Figure 1 shows that $94.09 \%$ of farmers from heavy metal-polluted areas in the Jiangxi Province believe that local heavy metal pollution results from the unreasonable disposal of three industries' wastes, $33 \%$ of farmers believe the source is actually sewage irrigation, while $2.46 \%$ of the respondents did not know the pollution source. No farmers believed that excessive use of fertilizer was the cause of the heavy metal pollution of farmland. According to the author's visit, the primary source of the heavy metal pollution in Jiangxi is derived from industrial waste. The primary reason is that there are many chemical processing plants in proximity to the settlements, and the discharged industrial wastewater directly enters the inhabited area. Even if there were no chemical processing plants near the village, the nearby water system was also contaminated by the sewage discharged from an upstream plant, resulting in the severe pollution of arable land.

Hunan Province is the first batch of heavy metal areas in China fallow pilot area. Fertilizer, sewage irrigation, and three industrial wastes are the sources of heavy metal pollution in this region. However, $22.86 \%$ of respondents did not know the source of heavy metal pollution. The farmers in Jiangxi Province had better awareness of the sources of farmland pollution than did those in Hunan Province.

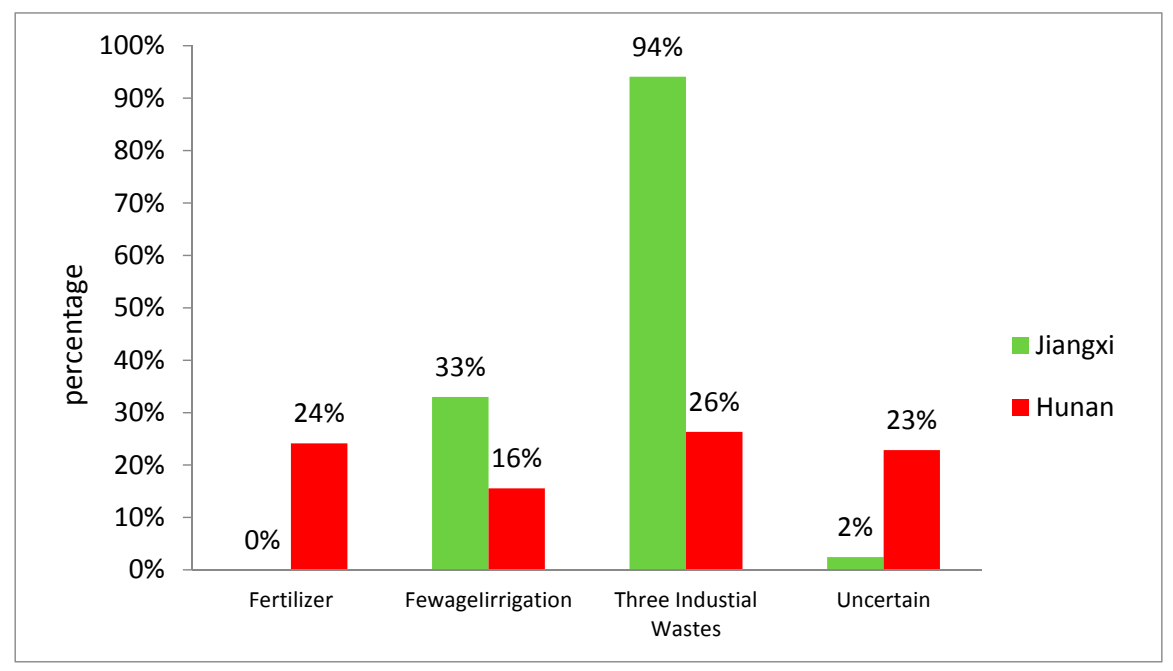

Figure 1. Statistics of farmers' awareness regarding the sources of heavy metal pollution in farmland areas.

(2) Statistical analysis of farmer's awareness of the dangers of heavy metal pollution in farmland areas

The results show responses to the question, "How much do you think land pollution affects you and your family's health?": A. seriously; B. slightly; C. not at all. As shown in Figure 2, among the sampled farmers in the heavily polluted areas of Jiangxi Province, $87 \%$ believed that the heavy metal pollution caused minor health damage, $9 \%$ said that physical health had been seriously affected, and only $4 \%$ believed that heavy metal pollution did not cause any damage to the body. Among the sampled farmers of the heavy metal-contaminated areas in Hunan Province, $45 \%$ believed that heavy 
metal pollution caused minor damage to the body. However, $41 \%$ of the respondents said they were not harmed. Only $14 \%$ of households indicated that they believed the body was seriously injured.

According to the above comparative analysis, most farmers from the Jiangxi heavy metal-polluted area clearly understood the dangers of heavy metal pollution. However, nearly half of the farmers from the heavy metal-contaminated areas in Hunan did not know that heavy metal pollution in farmland can cause harm to the body. These results show the level of the farmers' understanding of heavy metal pollution in the environment. The farmers were more concerned about the direct impacts of arable land and food, but did not see the indirect effects of heavy metal pollution as human health hazards.

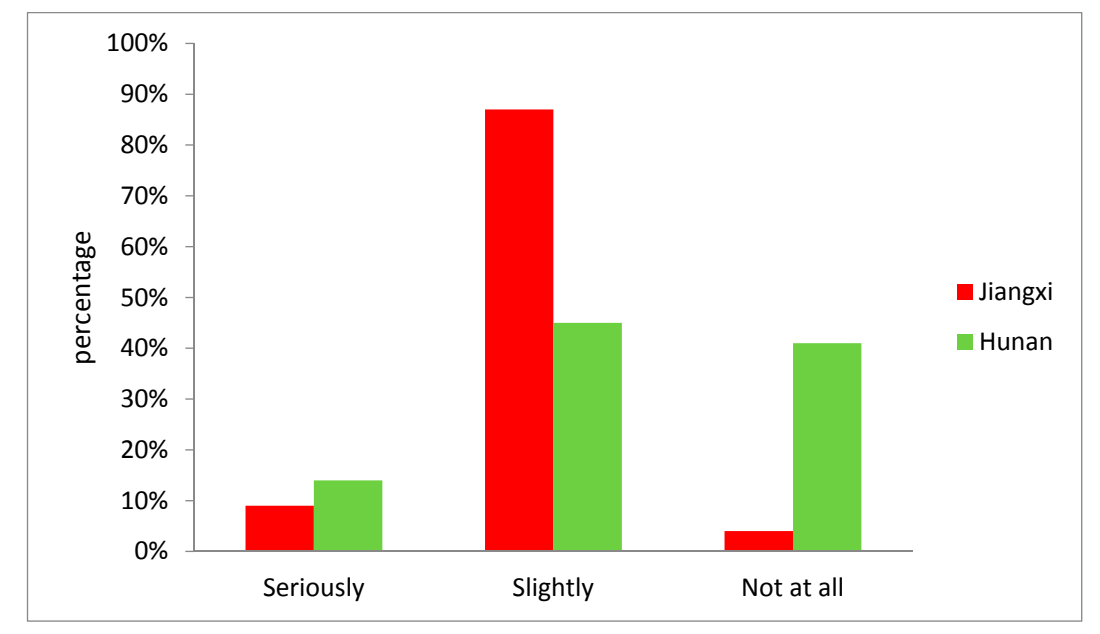

Figure 2. Statistics of farmers' awareness of the risk of heavy metal pollution in farmland.

\subsection{Characteristics of WTA of Surveyed Farmers in Jiangxi and Hunan Provinces}

Figure 3 shows the frequency distribution of social and economic characteristics of 203 respondents from Jiangxi Province and 315 respondents from Hunan Province. As can be seen from Figure 3, the proportion of men and women in Hunan Province is similar, the main age distribution of two provinces is in the range of 45-59, primary school students and junior high school students are the most numerous, the per capita income of Jiangxi Province concentrated in the area of 5001-6000 yuan; and that of Hunan Province concentrated around 4001-5000 yuan; the family size of the two provinces averaged 4-6 persons, and the average land area of the respondents was $0.6-1 \mathrm{mu}$, and most of these are part-time farmers.
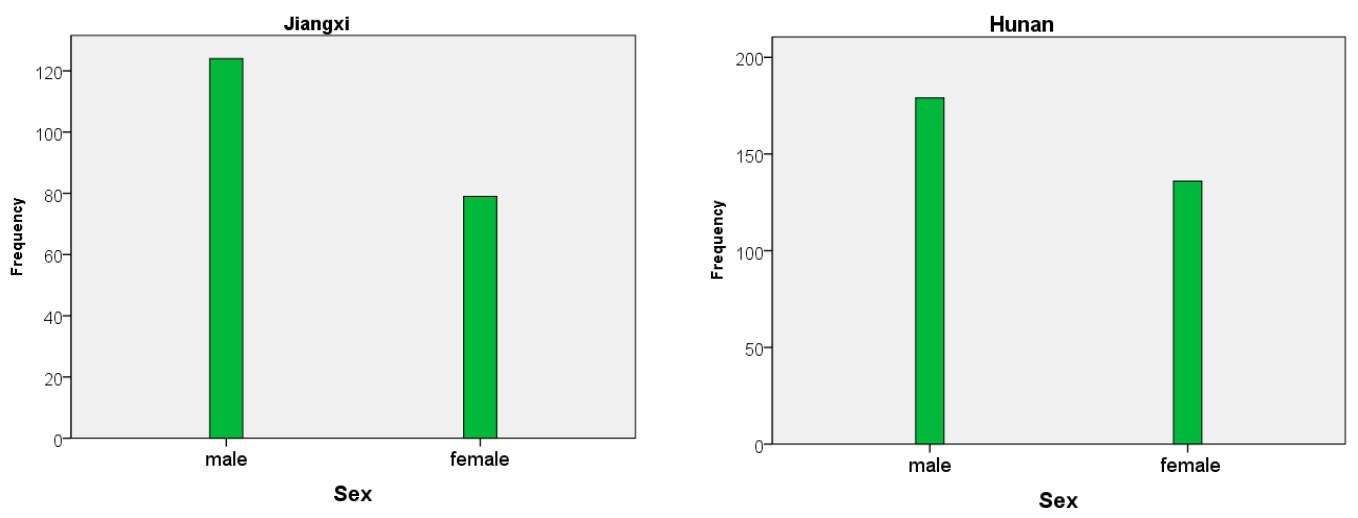

(a)

Figure 3. Cont. 

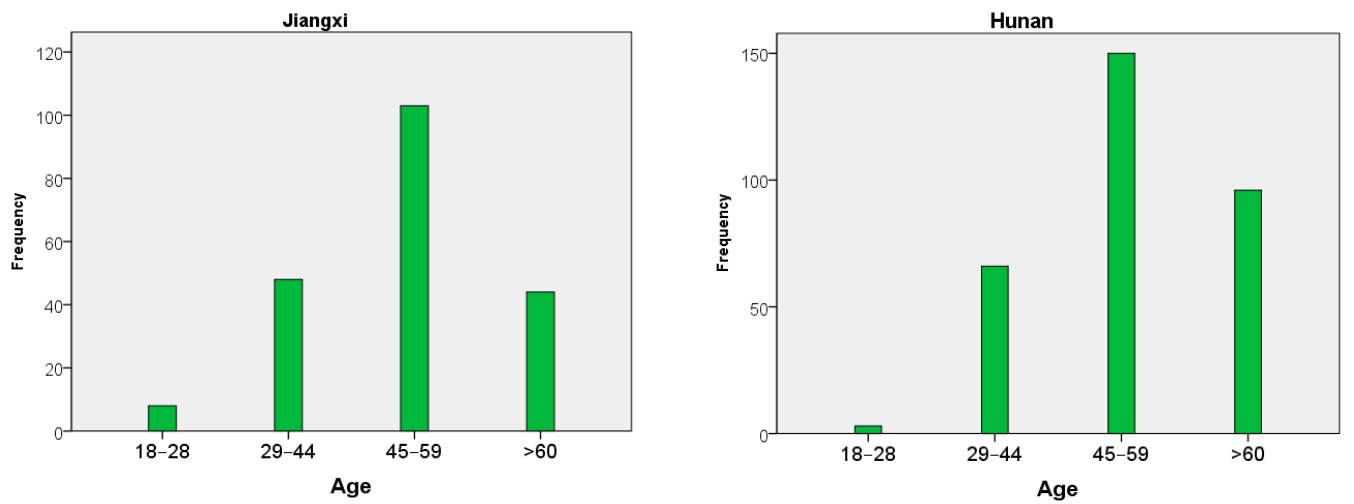

(b)
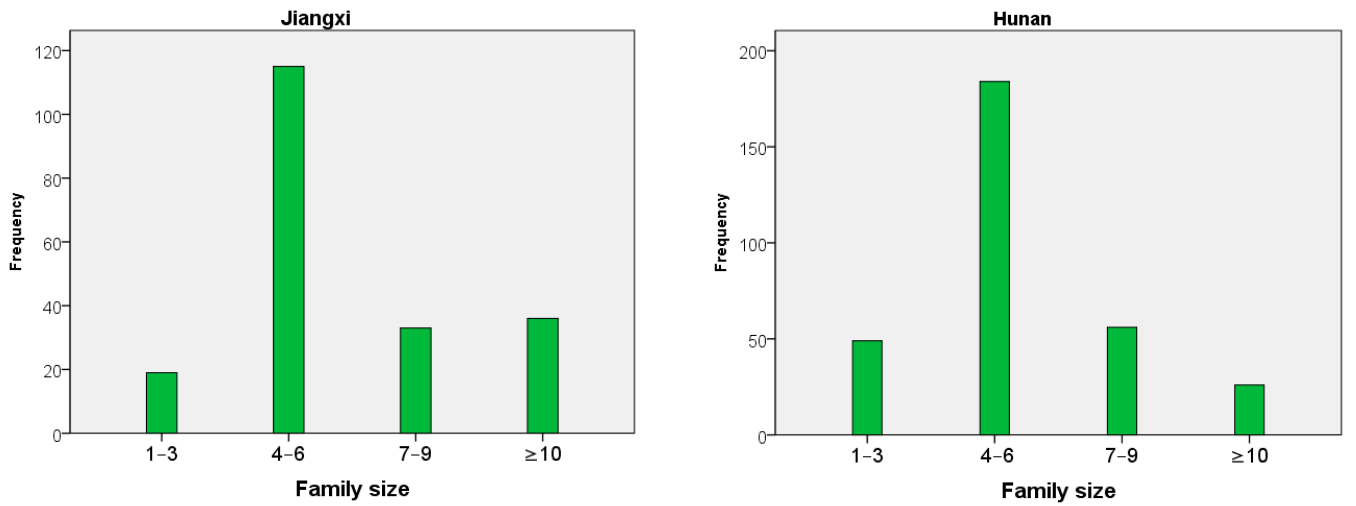

(c)
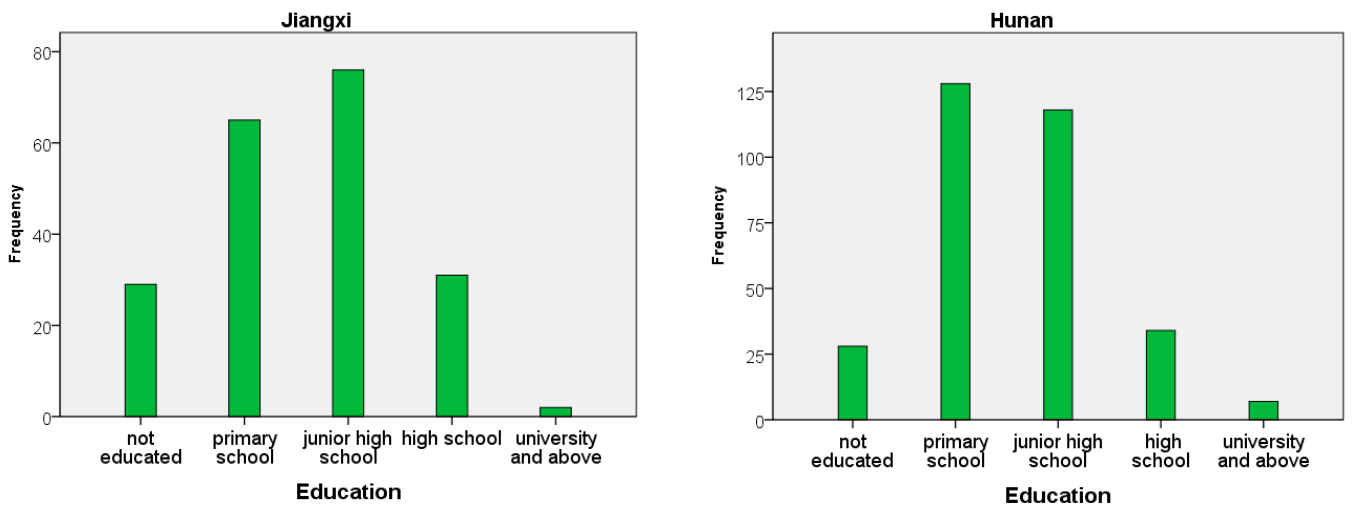

(d)
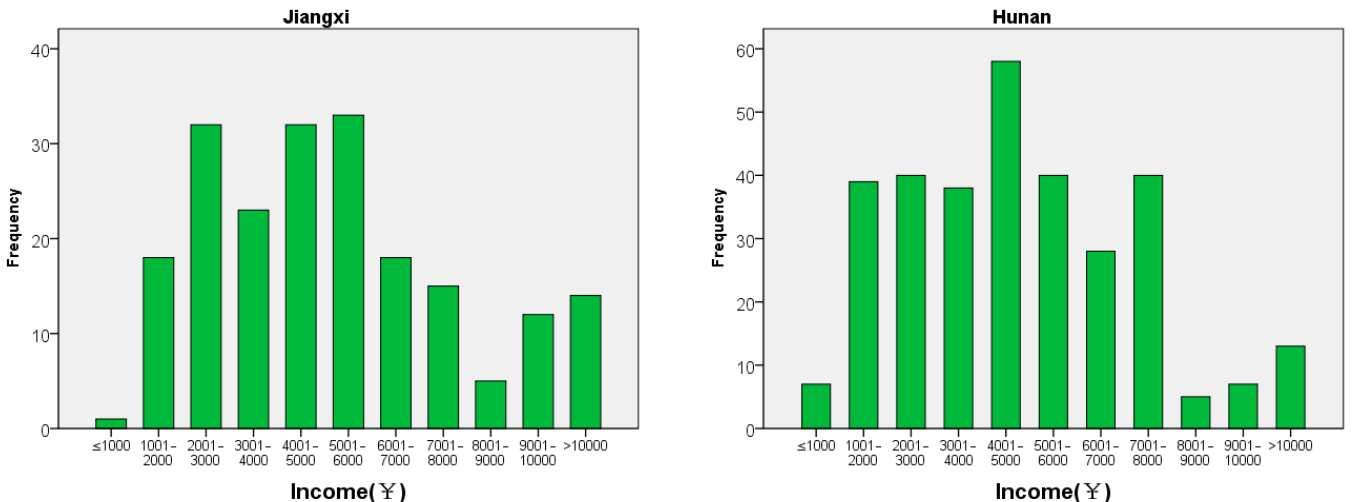

(e)

Figure 3. Cont. 

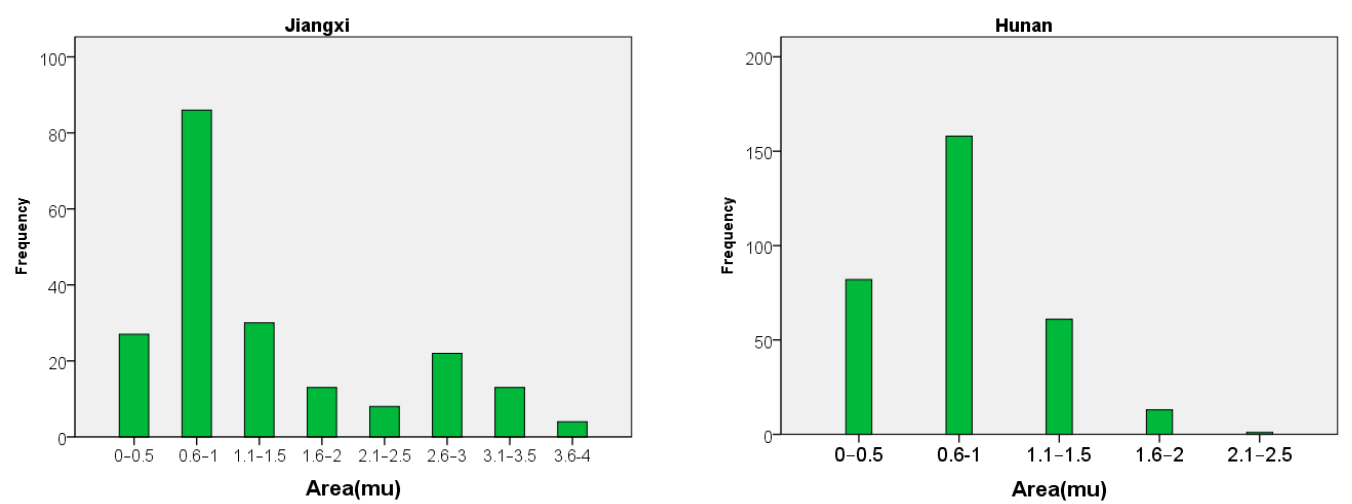

(f)
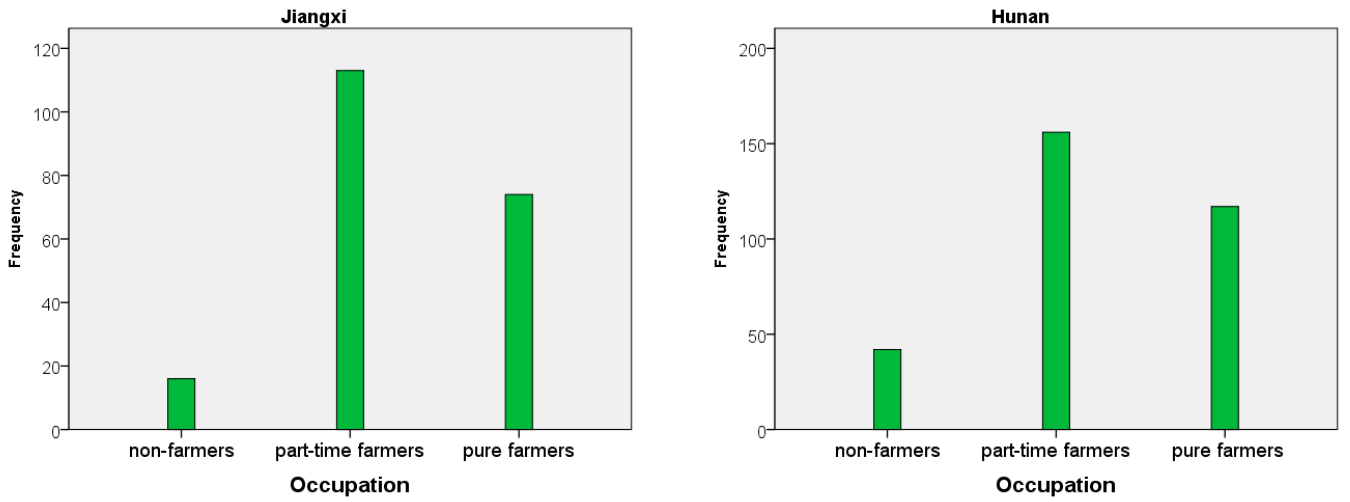

(g)

Figure 3. Frequency distribution of social and economic characteristics of 518 respondents. (a) Frequency distribution of sex; (b) Frequency distribution of age; (c) Frequency distribution of family size; (d) Frequency distribution of education; (e) Frequency distribution of income; (f) Frequency distribution of area; (g) Frequency distribution of occupation.

By investigating the WTA valuation problem in the questionnaire, we obtained the WTA distribution for the Jiangxi and Hunan Provinces, as shown in Table 1. Table 1 shows that in Jiangxi Province, the tender value is concentrated in the amounts of 500 yuan, 600 yuan, and 1000 yuan, whereas in Hunan Province, the tender value is mostly concentrated in the amounts of 700 yuan, 800 yuan, and 1000 yuan, three large amounts.

Regardless of the impact of the relevant variables such as the basic characteristics of the interviewee, only the expected value of WTA can be calculated using the following model:

$$
E(W T A)=\sum_{i}^{k} A W T A_{i} N_{i}
$$

where $N_{i}$ represents the $i$-th bid value selected by the interviewee, and $A W T A_{i}$ indicates the probability that the respondent selects the $i$-th bid value. The data are shown in Table 1 . The calculation was used to obtain the average WTA in Jiangxi Province $=902$ (yuan/mu) and the average WTA in Hunan Province $=902.26$ (yuan $/ \mathrm{mu}$ ). The WTA of the two provinces are nearly identical, possibly because they are located adjacent to each other, and food prices are highly comparable, separated by a few cents. 
Table 1. Accumulative frequency distribution of willingness to accept (WTA).

\begin{tabular}{cccccc}
\hline & Jiangxi & & \multicolumn{3}{c}{ Hunan } \\
\hline $\begin{array}{c}\text { WTA } \\
\text { (Yuan/mu) }\end{array}$ & $\begin{array}{c}\text { Absolute Frequency } \\
\text { (Number) }\end{array}$ & $\begin{array}{c}\text { Relative } \\
\text { Frequency (\%) }\end{array}$ & $\begin{array}{c}\text { WTA } \\
\text { (Yuan/mu) }\end{array}$ & $\begin{array}{c}\text { Absolute Frequency } \\
\text { (Number) }\end{array}$ & $\begin{array}{c}\text { Relative } \\
\text { Frequency (\%) }\end{array}$ \\
\hline 100 & 1 & 0.5 & 100 & 1 & 0.3 \\
300 & 9 & 4.4 & 400 & 3 & 1 \\
400 & 5 & 2.5 & 420 & 4 & 1.3 \\
500 & 30 & 14.8 & 450 & 3 & 1 \\
600 & 37 & 18.2 & 500 & 17 & 6.4 \\
700 & 23 & 11.3 & 600 & 19 & 29.2 \\
800 & 7 & 3.4 & 700 & 92 & 10.8 \\
900 & 4 & 2 & 800 & 34 & 5.1 \\
1000 & 31 & 15.3 & 900 & 16 & 27.3 \\
1100 & 1 & 0.5 & 1000 & 86 & 3.8 \\
1200 & 12 & 5.9 & 1200 & 12 & 1.6 \\
1300 & 6 & 3 & 1300 & 5 & 0.6 \\
1400 & 4 & 2 & 1400 & 2 & 3.5 \\
1500 & 18 & 8.9 & 1500 & 11 & 2.9 \\
1600 & 3 & 1.5 & 2000 & 9 & 0.3 \\
1800 & 1 & 0.5 & 10,000 & 1 & \\
2000 & 11 & 5.4 & & & \\
\hline
\end{tabular}

\subsection{Correlations between Respondents' Socioeconomic Background Factors and Willingness to Accept}

Theoretically, personal preferences, income conditions, and other socioeconomic characteristics directly affect WTA or willingness to pay (WTP) [45]. Considering the impact of these variables on willingness to accept, the maximum likelihood function estimation method is used to determine the relationship between the WTA of famers and the variables of its economic background. The logarithmic normal distribution of the willingness to accept used as the explanatory variable [46]. The model can be expressed as follows:

$$
\begin{gathered}
\ln \mathrm{WTA}=\alpha(\mathrm{P}, \mathrm{E}, \mathrm{S}, \mathrm{N})+\mu \\
\mathrm{E}(\mathrm{WTA})=\exp \left[\alpha(\mathrm{P}, \mathrm{E}, \mathrm{S}, \mathrm{N})+\frac{\delta^{2}}{2}\right]
\end{gathered}
$$

where P represents personal preference, E represents personal income, $\mathrm{S}$ represents individual social and economic information, and $\mathrm{N}$ represents the quantity or quality of resources. $\alpha$ represents the coefficient to be estimated; $\mu$ obeys $\left[0, \delta^{2}\right]$ the random distribution of random variables, $\ln W T A$ equals $\mu ; \delta^{2}$ is the variance; and $\alpha$ and $\delta^{2}$ can be derived from Equation (2).

In this study, based on previous research results [47-52] and field observations, factors that influence the willingness of farmers to accept compensation for heavy metal pollution of farmland from three categories: (1) farmer decision-maker characteristics, including gender, age, education, and occupation; (2) family characteristics, including the family size and per capita income; and (3) farmland conditions, comprising per capita arable land area.

The factors that affected the willingness to accept were examined using regression analysis assuming a linear model. The results of Equation (2) were determined using SPSS 20.0 and are shown in Table 2.

As is evident from Table 2, education level, average annual income, and per capita arable land area were significantly associated with willingness to accept the WTA. The estimated coefficient was tested at a significance level of $1 \%$. Among the variables, per capita arable land and the willingness of farmers to accept were positively correlated. This correlation indicates that the farmers' willingness to accept increased with increasing area of per capita arable land [53]. This correlation occurs primarily because a higher average farmland area per household is correlated with a higher profit from farmland and the farmers' willingness to accept. The willingness of farmers to accept is negatively correlated with farmers' education level and average annual income. That is, when their level of education is 
higher, the farmers' willingness accept is lower. This finding suggests that a higher level of education might increase a farmer's awareness of the dangers of agricultural pollution and, consequently, their support for agricultural land pollution control and ecological compensation policies [54]. The higher the average annual income, indicating that the respondents' income is not entirely dependent on land income, the lower the demand for abandonment of land compensation [55].

Table 2. Regression results of WTA in Jiangxi and Hunan Provinces.

\begin{tabular}{ccccccc}
\hline \multirow{2}{*}{ Variable } & \multicolumn{2}{c}{$\begin{array}{c}\text { Regression Coefficient } \\
\text { (Standard Deviation) }\end{array}$} & \multicolumn{2}{c}{$t$ Test Value } & \multirow{2}{*}{$\boldsymbol{i}$ Value } \\
\cline { 2 - 6 } & Jiangxi & Hunan & Jiangxi & Hunan & Jiangxi & Hunan \\
\hline Constant term & $7.481(79.549)$ & $6.685(95.261)$ & 40.83 & 50.305 & 0.000 & 0.000 \\
Sex $(\times 1)$ & $-0.086(15.157)$ & $0.03(11.387)$ & -1.953 & 0.971 & 0.052 & 0.333 \\
Age $(\times 2)$ & $0.021(9.181)$ & $0.037(12.084)$ & 0.661 & 1.667 & 0.509 & 0.096 \\
Education $(\times 3)$ & $-0.148(23.37)$ & $-0.071(12.838)$ & -4.778 & -3.704 & 0.000 & 0.000 \\
Family size $(\times 4)$ & $0.006(3.469)$ & $0.024(2.999)$ & 0.611 & 2.152 & 0.542 & 0.032 \\
Income $(\times 5)$ & $-0.084(0.005)$ & $-0.061(0.008)$ & -7.693 & -9.072 & 0.000 & 0.000 \\
Area $(\times 6)$ & $0.057(4.371)$ & $0.054(4.833)$ & 4.34 & 2.893 & 0.000 & 0.004 \\
Occupation $(\times 7)$ & $-0.05(11.72)$ & $0.151(12.823)$ & -1.558 & 5.31 & 0.121 & 0.000 \\
& \multicolumn{7}{c}{ Jiangxi R ${ }^{2}=0.646$} & & & \\
\hline
\end{tabular}

Gender was a significant mediating factor of the willingness to accept in Jiangxi Province, but not in Hunan Province. This result may be due to the fact that the Hunan Province sample featured a nearly balanced proportion of men to women. Jiangxi Province, by contrast, showed a significant negative correlation, indicating that men are willing to accept a higher level of compensation. This finding may be due to the fact that the proportion of male to female respondents in Jiangxi Province was 2:1. Respondents were mostly male, and men are the main source of labor for farming and are therefore more sensitive to the compensation amount. Neither age nor family size was significant in the Jiangxi model, but both showed a significant positive correlation in the Hunan model, suggesting that farmers' willingness to pay increases with age and household population $[56,57]$. According to the survey, most of the labor under the age of 45 is not performed by pure farmers but by part-time farmers and non-farmers. Therefore, in the case of additional income, these workers' demand for compensation is not as high as that of farmers, and they moreover believe that fallow land can enable them to liberate the labor force, increasing time to work and earn more money [54]. Furthermore, the larger size of the respondents' household, the greater the pressure on the limited income of farmland. Thus, the impact of farmer relinquishment of part of their economic benefits is high [56]. Therefore, the larger the family size, the higher the farmers' sensitivity to losing the income from agricultural activities. Farmer occupation was significantly and positively correlated with WTA in Hunan Province, with respondents that were exclusively farmers associated with higher compensation amounts. As such, farmers rely exclusively on farming income, fallowing reduces this main source of income; their WTA is therefore significantly higher than that of part-time farmers and non-farmers [57]. In contrast, in Jiangxi Province, occupation was not significantly associated with WTA. Based on our field observations, we speculate that this result might have occurred because the quality of the farmland of the majority of farmers in this province is quite poor; thus, farming entails the risk of financial loss, and farmers might therefore be eager for any compensation, regardless of the amount.

According to the parameters of Table 3, the following WTA model is obtained:

$$
\mathrm{E}(\mathrm{WTA})=\exp \left(\mathrm{C}+\alpha_{1} \overline{\mathrm{x} 1}+\alpha_{2} \overline{\mathrm{x} 2}+\alpha_{3} \overline{\mathrm{x} 3}+\alpha_{4} \overline{\mathrm{x} 4}+\alpha_{5} \overline{\mathrm{x} 5}+\alpha_{6} \overline{\mathrm{x} 6}+\alpha_{7} \overline{\mathrm{x} 7}+\frac{\delta^{2}}{2}\right)
$$


where $\alpha_{1}, \alpha_{2}, \alpha_{3}, \alpha_{5}, \alpha_{6}$ and $\alpha_{7}$ represent the coefficients of $\times 1, \times 2, \times 3, \times 4, \times 5, \times 6$ and $\times 7$, respectively; $\overline{x 1}, \overline{x 2}, \overline{x 3}, \overline{x 4}, \overline{x 5}, \overline{x 6}$ and $\overline{x 7}$ represent average values. Specific values are provided in Table 3.

Based on the above equation, the WTA is 839.34 (yuan/mu) in Jiangxi Province and 934.39 (yuan/mu) in Hunan Province. The WTA in Hunan Province is higher than that in Jiangxi Province. It can be seen from Figure 2 that the farmers in Hunan Province generally believe that the cultivated land they own has not been seriously polluted by heavy metals; thus, the amount of compensation they would accept is higher than in Jiangxi Province.

According to the author's survey, the primary form of agricultural production in the study area was the cultivation of one or two quarters. With the serious pollution of farmland, this form can produce 500-600 jin $/ \mathrm{mu}(1 \mathrm{jin}=0.5 \mathrm{~kg})$ of grain. Less polluted arable land could yield 1000-1200 jin/mu of grain. The rice purchase price was 1.2 yuan/jin in Jiangxi and Hunan Provinces in 2016. The production of more heavily polluted land was calculated at $500 \mathrm{jin}$. The net income was 600 yuan, and the less polluted farmland output was calculated at $1200 \mathrm{jin}$. Simultaneously, the net income was 1440 yuan. According to the survey, the local farmers' investment cost of planting the crops was calculated: fertilizer cost approximately 100 yuan/mu; pesticides cost approximately 60 yuan/mu; the annual grain purchase price was approximately 100 yuan $/ \mathrm{mu}$; and the machine farming costs were approximately 120 yuan/mu. The total cost was 380 yuan/mu. The average annual net income from agricultural products in the severely polluted areas of farmland was $220 \mathrm{yuan} / \mathrm{mu}$, and on the less polluted land, it was $1060 \mathrm{yuan} / \mathrm{mu}$. These calculations indicate that the local farmers' economic losses ranged from 220-1060 yuan and were caused by the abandonment of the pollution farmland. The average loss was 640 yuan, which means that the amount of the farmer's actual economic loss caused by the farmland fallow, was within the interval indicated by the willingness to accept, as determined by the survey. The difference between the statistical data of the questionnaire and the economic model and the actual economic loss of the affected households is approximately 200 yuan. This difference arises mainly because farmers do not know the exact amount of the resulting deviation. The CVM, the cost estimation method and the country's implementation of the fallow subsidy 700 yuan are closer in result.

Table 3. Sample farmers' preferences for compensation means.

\begin{tabular}{ccccc}
\hline \multirow{2}{*}{ Compensation Means } & \multicolumn{2}{c}{ First Choice (P) } & \multicolumn{2}{c}{ Second Choice (P) } \\
\cline { 2 - 5 } & Hunan & Jiangxi & Hunan & Jiangxi \\
\hline Cash & 237 & 116 & 39 & 30 \\
Technical support & 3 & 5 & 9 & 19 \\
Food subsidies & 10 & 12 & 57 & 38 \\
Social security & 19 & 40 & 43 & 40 \\
Arrange employment & 28 & 10 & 15 & 20 \\
Preferential policies & 2 & 3 & 3 & 6 \\
Land compensation & 1 & 4 & 3 & 9 \\
\hline
\end{tabular}

\subsection{Farmers' Preferences for the Method of Compensation}

\section{(1) Compensation method}

The compensation method can affect the farmers' implementation of fallowing [58]. Current compensation methods include compensation per losses according to pollution, crop yield output, health damage, crop market price, family population, farmland area, and the degree of loss at the pollution control stage. Currently, the compensation method in China is based on the number of mu. The following question was posed: "When your farmland is contaminated with pollution, how is your loss compensated?" Figure 4 presents the statistical analysis of the results of the compensation method preferred by the sample farmer's willingness to accept in heavy metal-polluted areas from Hunan and Jiangxi Provinces. This figure shows that the proportion of farmers who chose to be 
compensated for farmland area was the largest, accounting for $53 \%$ and $36 \%$ of the total number of farmers in Hunan and Jiangxi, respectively. These results indicate that most farmers still want to be compensated per the area of arable land, and the acceptance was relatively high. This outcome was followed by compensation per family population. In Hunan and Jiangxi, the total number of farmers preferring this method accounted for $43 \%$ and 33\%, respectively. According to the visits, the majority of the farmers' who chose this method did so because of the asymmetry of the household population and the holdings of arable land. The numbers of people who chose to be compensated per crop yield output and losses from pollution was less than $2 \%$ of the total number of samples in Hunan Province, while in Jiangxi Province, these values accounted for $13 \%$ and $7 \%$ of the total number of samples, respectively. The number who chose to be compensated according to the loss of the level of pollution control, and health damage was the lowest. As the numbers of farmers who chose these options were too small, these two options were excluded from the Hunan questionnaire. This result shows that farmers in both provinces are predominantly in favor of the current compensation method.

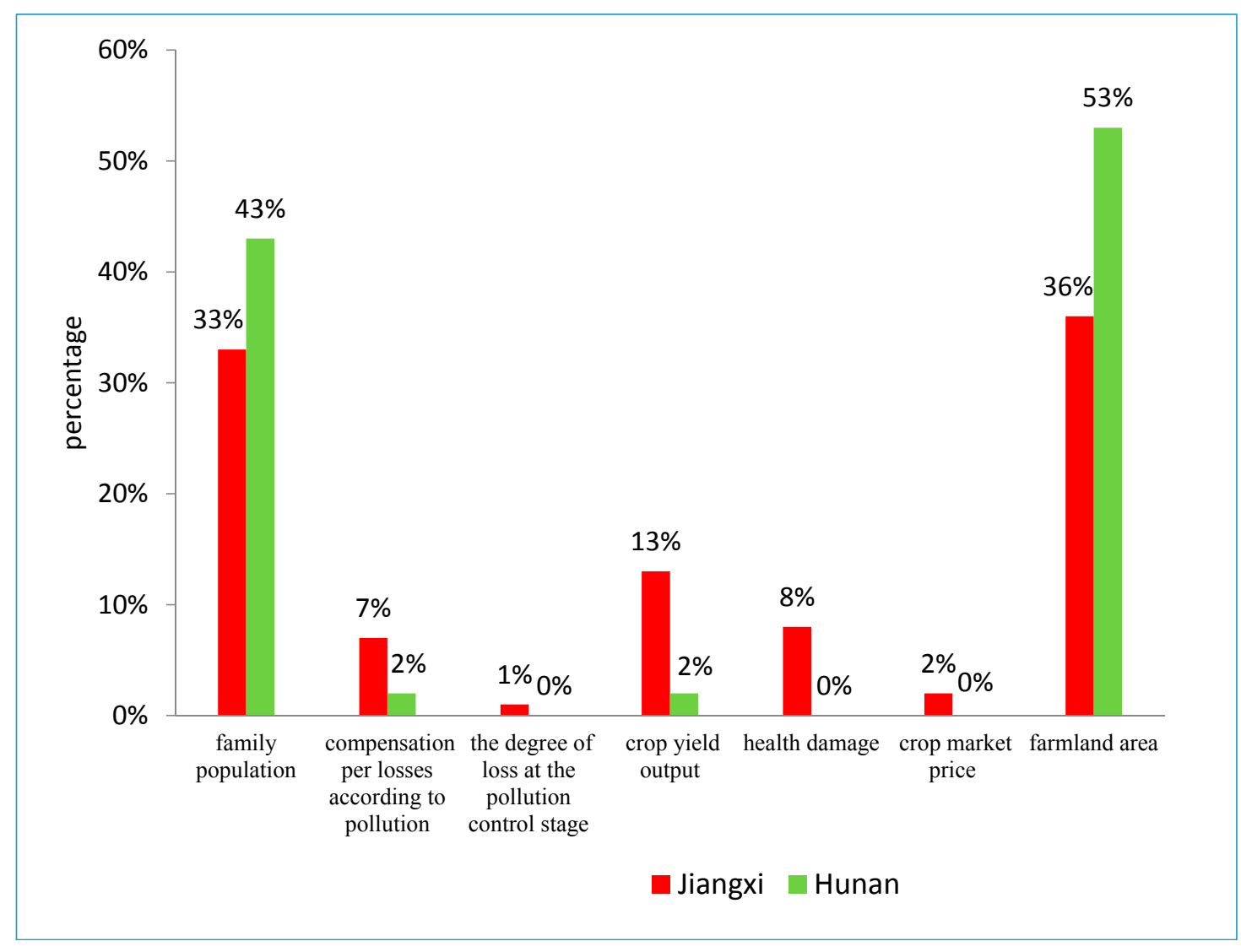

Figure 4. Sample farmers' preferred compensation method.

(2) Means of compensation

In addition to the amount of compensation and the compensation method, the means of compensation was also a key factor in the implementation of the fallow policy [59]. The current compensation means include cash, technical support, food subsidies, social security, arrangements for employment, preferential policies, and land compensation. The current fallow policy is in the form of cash payments. Table 3 shows the results of the statistical analysis of the farmers' willingness to accept by the compensation means. As this table shows, the first choice for the farmers from heavy metal-polluted areas in Hunan was by means of cash compensation, with 237 farmers preferring this method. This choice was followed by the arrangement of employment means, and the choice of land 
compensation was the least popular choice. In the Jiangxi heavy metal-polluted areas, the same first choice was by cash compensation, with 116 farmers preferring this method. This choice was followed by social security, and the least popular choice was preferential policies. This result shows that most farmers are most likely to accept cash payments.

The second choice of compensation means for farmers from the Hunan heavy metal-polluted areas was by food subsidies. This second choice was followed by social security and preferential policies, while land compensation was the least chosen. The most popular second choice of farmers from the Jiangxi heavy metal-polluted area was social security. This second choice was followed by food subsidies, and preferential policies were the least chosen. Per the comprehensive survey results of Jiangxi and Hunan farmers, most of the farmers preferred cash compensation, and social security and food subsidies were also preferred means of compensation.

\section{Conclusions and Policy Suggestions}

\subsection{Conclusions}

In this paper, the CVM method was used to get the farmer's true willingness to accept, a logistic model used to analyze the influencing factors of famers' WTA in the Hunan province and Jiangxi province, and the compensation standard of fallow heavy metal-polluted farmland was obtained. The main results are summarized follow.

(1) The awareness of heavy metal pollution of farmland in Jiangxi Province was greater than that in Hunan Province.

(2) Ignoring the impact of other factors, the WTA of farmers is 902 (yuan/mu) in Jiangxi Province and 902.26 (yuan/mu) in Hunan Province. Considering the influence of the basic characteristics of the respondents, the parameter estimation method determines that the WTA of farmers is 839.34 (yuan/mu) in Jiangxi Province and 934.39 (yuan/mu) in Hunan Province. There is little difference in the WTA between the two provinces, but the WTA in both regions are higher than the national compensation standards.

(3) The factors affecting the WTA of farmers in Jiangxi Province are gender, education level, average annual income and per capita arable land. The factors affecting the WTA of the farmers in Hunan Province are age, education level, family size, average annual income, per capita arable land area and occupation.

(4) At present, the means and methods of compensation for the implementation of the fallow policy are recognized by most farmers.

\subsection{Policy Recommendations}

(1) Farmland pollution levels should be stratified, and the appropriate compensation for fallowing should be reasonably determined [12]. The results revealed compensation standards of 839.34 (yuan/mu) in Jiangxi Province and 934.39 (yuan/mu) in Hunan Province. However, the pollution levels are not clearly delineated, and this leads farmers to the perception of pollution is not the same, so the willingness to accept is quite different. The different pollution levels of farmland should be associated with appropriate subsidy levels. To ensure reasonable cost outlays by the national government, more seriously polluted areas should receive more compensation; the farmers' willingness to participate would be improved, and this approach could save excess expenses.

(2) A diversification approach to realize the ecological compensation mode of heavy metal pollution in farmland areas. The survey found that some respondents preferred the choice of cash as a single compensation means. Others chose other compensation methods. Therefore, the relevant government departments can adapt to the preferences of local residents regarding ecological compensation to develop and provide a variety of forms of ecological compensation, and to improve the heavy metal pollution ecological compensation mechanism of arable land. 
(3) The extent of the heavy metal-polluted farmland fallow policy and farmers' awareness of the hazards of polluted arable land should be increased. As can be seen from this article, the level of education is significantly related to the farmers' willingness to accept. Therefore, improving the quality of farmers' education could generate publicity and help them fully understand the strategic importance of heavy metal-polluted land fallowing. In particular, improving the understanding of a new generation of farmers' with regard to arable land heavy metal pollution is one of the most important tasks for improving the current performance of farmland protection.

\subsection{Discussion}

In this study, the ecological compensation standard for heavy metal pollution of cultivated land was estimated as 934.39 (yuan/mu) in Hunan Province and 839.34 (yuan/mu) in Jiangxi Province. However, developing a compensation mechanism for fallowing farmland is a complex, multifaceted and multidimensional task. The compensation standard proposed in this paper is different from that proposed by policy. This finding indicates that ecological compensation standards cannot be "one size fits all" and should be determined based on research. The following shortcomings are identified as the key research directions for the future.

First, this article macroscopically measured the compensation standards of heavy metal pollution of cultivated land. However, due to China's vast territory, the region's food prices and economic development and the wide variation in farmland resources, these standards cannot be uniformly approached. The question of how to devise differentiated compensation standards for different regional characteristics is an important research direction for the future.

Second, the compensation standard recommendations are based on the results of the questionnaire. However, since the CVM and estimation of nonmarket value are based on the consumer's choice and behavior in a false market, the CVM data assessment is used in a hypothetical market. Therefore, we must develop an accurate market simulation. Regardless of the respondent's understanding, the quality of the investigators, or other requirements, error must be avoided. However, because the questionnaire was not sufficiently detailed, and for other reasons, it was difficult to eliminate the errors. In the future, we will improve the method for measuring the nonmarket value of cultivated land resources to more effectively set the compensation standards.

The CVM method in this study only consider the farmers' willingness. Otherwise, a good policy should consider all the relevant stakeholders rather than ignoring one or the other. As both the government and farmers are key stakeholders here, the results will be more convincing.

Third, there is a growing body of literature stating that monetary compensation and economic benefits are not the primary motivating force for engagement in ecosystem management. For example: farmers' understanding of ecological protection [60]; fairness of ecological compensation distribution [61]; the spatial conditions of land [62], and; other factors also have important influence on farmers' willingness to participate an ecosystem management. In future research, we need to consider those in detail.

Finally, due to the separation of rural land rights in China, there are many land transfer activities, which means that the landowners and land operators are not always the same people. However, land property rights have a great impact on farmers' willingness to accept [63]. Hence, the compensation object should be clear. This article does not consider this aspect in detail, and thus, the compensation recipient is generalized. Therefore, in the next study, we will examine the compensation recipient and how to balance the economic interests of each compensation recipient for a broad range of study assessments.

Based on the above conclusions, it can be concluded that a change in farmer livelihood will directly impact farmers' decision-making behaviors [64]. Farmer awareness of pollution will also greatly affect farmers' willingness to accept [57]. The authors of the present study argue that the government should strengthen public opinion guidance, promote public participation, augment the roles of rural organizations, publicize and provide education regarding heavy metal pollution and 
environmental protection knowledge, and improve farmer awareness [65]. The government should scientifically plan and use land to guarantee the provision of public goods such as ecological welfare and food security [66]. In addition, the farmers' own assets should be considered, and the livelihood capital of farmers should be improved. According to the needs of different types of farmers, different types of ecological compensation measures should be developed [64]. By implementing these changes, farmers will actively take the initiative to cooperate with the government to implement the policy, improving the implementation of ecological compensation policy.

Acknowledgments: This study was supported by the Key Projects of the National Social Science Fund of China (No. 15AZD075); the Major Projects of the National Social Science Fund of China (No. 15ZDB159); the National Natural Science Foundation of China (No. 41561040); the Natural Science Foundation of Jiangxi Province (No. 20143ACB21023); the Technology Foundation of Jiangxi Education Department of China (No. KJLD14033 \& No. GJJ160431) and the Fok Ying-Tung Fund (No. 141084).

Author Contributions: Hualin Xie developed the original idea for the study. Xue Xie and Qing Wu were responsible for data collection. Xue Xie, Cheng Shu and Hua Lu conducted the data analyses. All the authors contributed to drafting the manuscript and approved the final version of the manuscript.

Conflicts of Interest: The authors declare no conflict of interest.

\section{References}

1. Singh, O.; Labana, S.; Pandey, G. Phytoremediation: An overview of metallic ion decontamination from soil. Appl. Microbiol. Biotechnol. 2003, 61, 405-412. [CrossRef] [PubMed]

2. Xie, H.L.; He, Y.F.; Xie, X. Exploring the factors influencing ecological land change for China's Beijing-Tianjin-Hebei region using big data. J. Clean. Prod. 2017, 142, 677-687. [CrossRef]

3. Xie, H.; Wang, W.; Yang, Z.H.; Choi, Y. Measuring the sustainable performance of industrial land utilization in major industrial zones of China. Technol. Forecast. Soc. Chang. 2016, 112, 207-219. [CrossRef]

4. Li, Y.M.; Wang, X.; Hao, L.; Liu, Y.; Jiang, L.G. An Analysis on Treatment of Heavy-Metal Soil Contamination: Characteristics and Determinants of Farmers' Treatment Methods. Chin. Rural Econ. 2017, 1, 58-67. (In Chinese)

5. Chen, W.P.; Lu, S.D.; Zhang, W.L.; Yi, L.; Jiao, W. Ecological risks and sustainable utilization of reclaimed water and wastewater irrigation. Acta Ecol. Sin. 2014, 34, 163-172. (In Chinese)

6. Zhao, Q.G.; Teng, Y.; Huang, G.Q. Consideration about Exploring Pilot Program of Farmland Rotation and Fallow System in China. Ecol. Environ. Sci. 2017, 26, 1-5. (In Chinese)

7. Yang, Q.Y.; Xin, G.X.; Jiang, J.L.; Chen, Z.T. The Comparison and Implications of Crop Rotation and Fallow in the Western Countries and East Asia. Chin. Land Sci. 2017, 31, 71-79. (In Chinese)

8. Wei, H.B.; Wu, K.N.; Zhao, H.F.; Xia, M.F.; Liu, Q.Q. Spatial distribution characteristics of cultivated land quality gradation in the main grain production area of central China. Res. Sci. 2015, 37, 1552-1560. (In Chinese)

9. Johnson, K.A.; Dalzell, B.J.; Donahue, M.; Gourevitch, J.; Johnson, D.L.; Karlovits, S.; Keeler, B.; Smith, J.T. Conservation Reserve Program (CRP) lands provide ecosystem service benefits that exceed land rental payment costs. Ecosyst. Serv. 2016, 18, 175-185. [CrossRef]

10. Kirwan, B.; Lubowski, R.N.; Roberts, M.J. How Cost-Effective Are Land Retirement Auctions? Estimating the Difference between Payments and Willingness to Accept in the Conservation Reserve Program. Am. J. Agric. Econ. 2006, 87, 1239-1247. [CrossRef]

11. Xie, H.L.; YAO, G.R.; Liu, G.Y. Spatial evaluation of ecological importance based on GIS for environmental management: a case study in Xingguo County of China. Ecol. Indic. 2015, 51, 3-12. [CrossRef]

12. Wu, Q.; Xie, H.L. A Review and Implication of Land Fallow System Research. J. Res. Ecol. 2017, 8, $223-231$.

13. Baylis, K.; Peplow, S.; Rausser, G.; Simon, L. Agri-environmental policies in the EU and United States: A comparison. Ecol. Econ. 2008, 65, 753-764. [CrossRef]

14. Cason, T.N.; Gangadharan, L. Auction Design for Voluntary Conservation Programs. Am. J. Agric. Econ. 2004, 86, 1211-1222. [CrossRef]

15. Suter, J.F.; Poe, G.L.; Bills, N.L. Do Landowners Respond to Land Retirement Incentives? Evidence from the Conservation Reserve Enhancement Program. Land Econ. 2008, 84, 17-30. [CrossRef] 
16. Babcock, B.A.; Lakshminarayan, P.G.; Wu, J.J.; Zilberman, D. The economics of a public fund for environmental amenities: A study of CRP contracts. Am. J. Agric. Econ. 1996, 78, 961-971. [CrossRef]

17. Feather, P.; Hellerstein, D.; Hansen, L.R. Economic valuation of environmental benefits and the targeting of conservation programs: The case of the CRP. Soc. Sci. Electron. Publ. 1999, 36, 2445-2453.

18. Ribaudo, M.O. Natural resources and users benefit from the Conservation Reserve Program. In Proceedings of the Symposium on System Theory, Cookeville, TN, USA, 11-13 March 1990; U.S. Department of Agriculture: Washington, DC, USA, 1900; pp. 537-557.

19. Xie, H.L.; Cheng, L.J.; Lv, T.G. Factors Influencing Farmer Willingness to Fallow Winter Wheat and Ecological Compensation Standards in a Groundwater Funnel Area in Hengshui, Hebei Province, China. Sustainability 2017, 9, 839. [CrossRef]

20. Hu, Z.; Liu, D.; Kong, D.; Xin, L. Rate calculation of "subsides of grazing prohibition" in grassland eco-compensation based on opportunity cost method. J. Arid Land Resour. Environ. 2017, 2, 63-68. (In Chinese)

21. Claassen, R.; Cattaneo, A.; Johansson, R. Cost-effective design of agri-environmental payment programs: U.S. Experience in theory and practice. Ecol. Econ. 2008, 65, 737-752. [CrossRef]

22. Pagiola, S.; Ramirez, E.; Gobbi, J.; de Haan, C.; Ibrahim, M.; Murqueitio, E.; Ruiz, J.P. Paying for the environmental services of silvopastoral practices in Nicaragua. Ecol. Econ. 2007, 64, 347-385. [CrossRef]

23. Kalacska, M.; Sanchez-Azofeif, G.; Rivard, B.; Calvo-Alvarado, J.C.; Quesada, M. Basedline assessment for environmental services payments from satellite imagery: A case study from Costa Rice and Mexico. J. Environ. Manag. 2008, 88, 348-359. [CrossRef] [PubMed]

24. Fischel, W.A. The Economics of Zoning Laws: A Property Rights Approach to American Land Use Controls; The Johns Hopkins University Press: Baltimore, MD, USA, 1987.

25. Liu, X.H.; Yu, X.J. Study on Characteristics and Countermeasures of Heavy Metal Pollution in Yangtze River Delta. Ecol. Econ. 2010, 10, 164-166. (In Chinese)

26. Hanemann, M.W. Discrete continuous Models of Consumer Demand. Econometrica 1984, 52, 541-562. [CrossRef]

27. Davis, R.K. Recreation planning as an economic problem. Nat. Res. J. 1963, 3, 239-249.

28. Hoehn, J.P.; Randall, A. A satisfactory benefit cost indicator from contingent valuation. J. Environ. Econ. Manag. 1987, 14, 1226-1247. [CrossRef]

29. Chen, J. Study on the Application of CVM in the Social Benefits Valuation of Urban Mass Transit. Adv. Mater. Res. 2013, 734-737, 1625-1628. (In Chinese) [CrossRef]

30. Park, S.H.; Jung, W.J.; Kim, T.H.; Lee, S.-Y.T. Can Renewable Energy Replace Nuclear Power in Korea? An Economic Valuation Analysis. Nucl. Eng. Technol. 2016, 48, 559-571. [CrossRef]

31. Liziński, T.; Wróblewska, A.; Rauba, K. Application of CVM method in the evaluation of flood control and water and sewage management projects. J. Water Land Dev. 2015, 24, 41-49. [CrossRef]

32. Griffiths, J.M.; King, D.W.; Lynch, T. Taxpayer Return on Investment in Florida Public Libraries: Summary Report; State Library and Archives of Florida: Tallahassee, FL, USA, 2010.

33. Lindhjem, H.; Mitani, Y. Forest owners' willingness to accept compensation for voluntary conservation: A contingent valuation approach. J. For. Econ. 2012, 18, 290-302. [CrossRef]

34. Maler, K.G. Handbook of Environmental Economics-Valuing Environmental Changes; Handbook of environmental economics; Blackwell: Oxford, UK, 1995; pp. 125-126.

35. Vedel, S.E.; Jacobsen, J.B.; Bo, J.T. Forest owners' willingness to accept contracts for ecosystem service provision is sensitive to additionality. Ecol. Econ. 2015, 113, 15-24. [CrossRef]

36. Qian, X.; Wang, D.; Ma, L. Benefit Valuation on the Improvement of Street Parks: The CVM Application in Urban Planning. Urban Plan. Forum 2010, 3, 41-50. (In Chinese)

37. Yuan, S.B.; Wang, H.Z.; Cao, Q. A Case Study of Using CVN to Measure Social Value of Libraries Abroad. Libr. J. 2011, 8, 79-83. (In Chinese)

38. Li, Y.Z.; Xu, N.W. Studies of the Management System of Yangtze River National Park Based on CVM. Resour. Environ. Yangtze Basin 2016, 1, 1509-1519. (In Chinese)

39. Yang, X.; Cai, Y.Y.; Zhang, A.L. Estimation of Farmland Eco-Compensation Horizontal Transferring Payment Amount in Wuhan Metropolitan Area-From the perspective of Spillover Ecological Value Measured by Choice Experiment. Resour. Environ. Yangtze Basin 2017, 3, 368-375. (In Chinese)

40. Yu, Y.H. Farmer's willingness to accept for maintaining the grain for green: An empirical analysis based on Wanzhou district in Chongqing. J. Arid Land Resour. Environ. 2015, 4, 65-70. (In Chinese) 
41. Zhou, C.; Li, G.P. A Study on the Willingness and the Influencing Factors of Farmers' Ecological Service Supply-Based on the Survey of 406 Farmers in the Water Resources Area of Southern Shaanxi. Econ. Sci. 2015, 5, 107-117. (In Chinese)

42. Zheng, X.M.; Bai, T.X. Willingness to Pay for Eco-compensation and Its Influencing Factors of the Residents in the Cities Getting Drinkable Water from Dahuofang Reservoir. Wetl. Sci. 2016, 1, 65-71.

43. Hu, W.H. Characteristics of grain production in Central China and its influence on national grains. Geogr. Res. 2008, 4, 885-896. (In Chinese)

44. Zhou, C.; Li, G.P. The Influencing Factors for Willingness to Pay of Payment for Watershed Services: A Case of the Water Receiving Area of Zhengzhou City of the Middle Route Project of the South-North Water Transfer Project. Econ. Geogr. 2015, 6, 38-46. (In Chinese)

45. Zheng, H.X.; Zhang, L.B. Research on the Standardization of Compensation for the Service of Eco System in River Valley. Environ. Prot. 2006, 35, 241-244. (In Chinese)

46. Jack, B.K.; Leimona, B.; Ferraro, P.J. A Revealed Preference Approach to Estimating Supply Curves for Ecosystem Services: Use of Auctions to Set Payments for Soil Erosion Control in Indonesia. Conserv. Biol. 2009, 23, 359-367. [CrossRef] [PubMed]

47. Wang, C.; Cui, L.; Mao, X.; Wen, Y. Comparative studies on the farmers' willingness to accept eco-compensation in wetlands nature reserve. Acta Ecol. Sinca 2012, 17, 5345-5354. (In Chinese) [CrossRef]

48. Zhou, Y.; Yang, Q.; Xin, G.; Feng, Y.; Dai, P. The impact of rural households' concurrent business behaviors response on the housing land-use pattern in poor mountain area: Based on a survey of 568 households in Yunyang County, Chongqing. Geogr. Res. 2010, 10, 1767-1779. (In Chinese)

49. Yin, K.; Xiao, Y. Empirical Research on Household Willingness and Its Caused Factors for economic compensation of Eco-fallow in the Water-level Fluctuation Zone of the Three Gorges Reservoir Area. Sci. Geogr. Sin. 2015, 9, 1123-1129. (In Chinese)

50. Li, H.; Cai, Y. Livelihood Diversity and Farmer Participate in Farmland Ecological Compensation Policy Response: The Case Study of Minhang District, Shanghai and Zhangjiagang District, Suzhou. J. Nat. Res. 2014, 10, 1696-1708. (In Chinese)

51. Shi, P.; Ju, J. Study on ecological migration willingness and its influencing factors: A case of Ankang. Shaanxi. J. Chin. Agric. Univ. 2013, 18, 218-228. (In Chinese)

52. Zhang, F.; Zhao, X.; Tian, Y.; Hou, C.; Zhang, L. Social Capital and Farmer Willingness to Participate in Ecological Compensation for Three Sites in Gansu. Res. Sci. 2013, 9, 1821-1827. (In Chinese)

53. Liu, Y.P.; Li, G.; Chen, X.; Jin, J.X.; Zhou, W.S.; Yang, Y.D. Monetary Valuation of the Non-Use Value of Recreational Resources in Huangguoshu Scenically Resort based on WTP and WTA Methods. Res. Sci. 2008, 3, 431-439. (In Chinese)

54. Makarius, C.S.; Lalika, P.M.; Yonika, M.N.; Goddy, J.S. Willingness to pay for watershed conservation: Are we applying the right paradigm? Ecohydrol. Hydrobiol. 2017, 17, 33-45.

55. Xia, J.Q.; Luo, Y.M. Some Problems in Current Cultivated Soil Pollution Survey and Assessment in China. Soils 2006, 5, 667-670. (In Chinese)

56. Xu, D.W.; Liu, C.Y.; Chang, L. A Study on the Disparity of WTP and WTA of the Basin's Willingness to Compensate: Based on the Residents' CVM Investigation in the Middle Liaohe Drainage Basin. J. Nat. Res. 2013, 3, 402-409. (In Chinese)

57. Li, G.D.; Fang, C.L.; Qiu, D.C.; Wang, L.P. Impact of farmer households' livelihood assets on their options of economic compensation patterns for farmland protection. J. Geogr. Sci. 2014, 2, 331-348. (In Chinese) [CrossRef]

58. Dai, Q.W. Research on the eco-compensation standards and modes: Taking Maoershan National Nature Reserve of Guangxi Province as an example. Acta Ecol. Sinica 2014, 17, 5114-5123. (In Chinese)

59. Herzon, I.; Mikk, M. Farmers, perceptions of biodiversity and their willingness to enhance it through agri-environment schemes: A comparative study from Estonia and Finland. J. Nat. Conserv. 2007, 15, 10-25. [CrossRef]

60. Moon, K.; Cocklin, C. Participation in biodiversity conservation: Motivations and barriers of Australian landholders. J. Rural Stud. 2011, 27, 331-342. [CrossRef]

61. Sommmerville, M.; Jones, J.P.G.; Rahajaharison, M.; Milner-Gulland, E.J. The role of fairness-Based payment for Environment Services interventions: A case study from Menabe, Madagascar. Ecol. Econ. 2008, $66,270-274$. 
62. Xie, J.; Cai, Y. The impacts of farmer livelihood endowment on participation effectiveness in farmland conservation compensation policy: Chengdu and Suzhou as typical innovational practice areas. Resour. Sci. 2016, 11, 2082-2094. (In Chinese)

63. Xie, H.L.; Lu, H. Impact of Land Fragmentation and Non-Agricultural Labor Supply on Circulation of Agricultural. Land Use Policy 2017, 68, 355-364. [CrossRef]

64. Li, H.; Cai, Y. The influence of livelihood capital on intention of protecting cultivated land of farmers: A case study in the three towns in Chengdu area. J. Glaciol. Geocryol. 2015, 2, 545-554. (In Chinese)

65. Liu, A.; Xu, D.; Xie, F.; Cao, M.; Liu, Z. On Measure of Farmer Livelihoods Capital Based on Factors Affecting Livelihood Strategies-A Case Study of Sichuan Province. J. Southwest China Norm. Univ. 2015, 12, $59-65$. (In Chinese)

66. Yao, G.R.; Xie, H.L. Rural spatial restructuring in ecologically fragile mountainous areas of southern China: A case study of Changgang Town, Jiangxi Province. J. Rural Stud. 2016, 47, 435-448. [CrossRef]

(C) 2017 by the authors. Licensee MDPI, Basel, Switzerland. This article is an open access article distributed under the terms and conditions of the Creative Commons Attribution (CC BY) license (http://creativecommons.org/licenses/by/4.0/). 